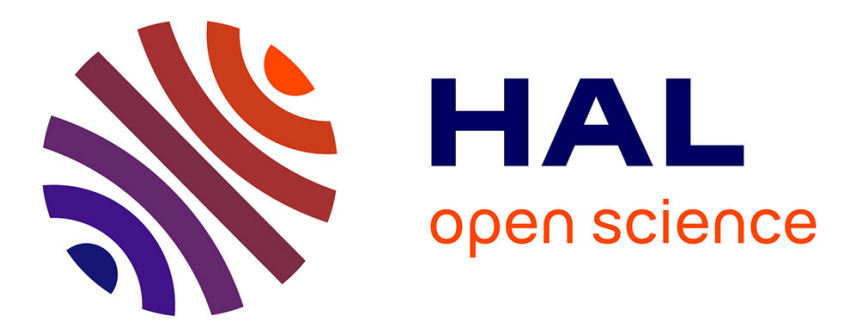

\title{
A simulation model for customer-supplier cooperation in the telecom supply chain
}

\author{
Jaouher Mahmoudi, Jacques Lamothe, Caroline Thierry
}

\section{To cite this version:}

Jaouher Mahmoudi, Jacques Lamothe, Caroline Thierry. A simulation model for customer-supplier cooperation in the telecom supply chain. International Journal of Business Performance Management, 2007, 9 (2), 10.1504/IJBPM.2007.011862 . hal-01787035

\section{HAL Id: hal-01787035 \\ https://hal.science/hal-01787035}

Submitted on 8 Nov 2019

HAL is a multi-disciplinary open access archive for the deposit and dissemination of scientific research documents, whether they are published or not. The documents may come from teaching and research institutions in France or abroad, or from public or private research centers.
L'archive ouverte pluridisciplinaire HAL, est destinée au dépôt et à la diffusion de documents scientifiques de niveau recherche, publiés ou non, émanant des établissements d'enseignement et de recherche français ou étrangers, des laboratoires publics ou privés. 


\title{
A simulation model for customer-supplier cooperation in the telecom supply chain
}

\section{Jaouher Mahmoudi*}

Office National d'Etudes et de Recherches Aérospatiales

ONERA/DCSD

BP 4025 - F-31055 Toulouse Cedex 4, France

Fax: +33 562252564

E-mail: mahmoudi@enstimac.fr

*Corresponding author

Ecole des Mines d'Albi Carmaux

Centre de Génie Industriel

Campus Jarlard

81013 Albi CT Cedex 09, France

\section{Jacques Lamothe}

Ecole des Mines d'Albi Carmaux

Centre de Génie Industriel

Campus Jarlard

81013 Albi CT Cedex 09, France

E-mail: lamothe@enstimac.fr

\section{Caroline Thierry}

Office National d'Etudes et de Recherches Aérospatiales ONERA/DCSD

BP 4025 - F-31055 Toulouse Cedex 4, France

Fax: +33 562252564

E-mail: thierry@univ-tlse2.fr

Université Toulouse II le Mirail

Département de mathématiques et Informatique

5 Allées Antonio Machado

F-31058 Toulouse Cedex 9, France

\begin{abstract}
Telecom supply chains are subject to instabilities and uncertainties that make substantial the risks handled by the chain actors. This paper demonstrates that the exchange or sharing of reliable information improves both actors' and SC's performance. In particular, this paper presents a system and implementation methodology that evaluates the risks of an actor's behaviour (capacity-requirements-planning behaviour, supply behaviour) on the performance of other actors and of the whole supply chain.
\end{abstract}

Keywords: telecom supply chain; simulation; capacity; performance measurement; risk management. 
Biographical notes: J. Mahmoudi is a $\mathrm{PhD}$ student of Ecole Nationale Supérieure de l'Aéronautique et de l'Espace (Sup'Aero). His research is done in the Industrial Engineering Department of the Ecole des Mines d'Albi-Carmaux and in Office Nationale d'Etudes et de Recherches Aérospatiales (ONERA) and concerns telecom supply chain simulation.

J. Lamothe is an Associate Professor at the Industrial Engineering Department of the Ecole des Mines d'Albi-Carmaux. He received his PhD in 1996 from Ecole Nationale Supérieure de l'Aéronautique et de l'Espace (Sup'Aero). His main research concerns the design and the control of supply chains.

C. Thierry is an Associate Professor at the University of Toulouse 2 Le Mirail. She received her $\mathrm{PhD}$ in 1994 from Ecole Nationale Supérieure de l'Aéronautique et de l'Espace (Sup'Aero). Her research in ONERA mostly focuses on models and decision systems in supply chain management.

\section{Introduction}

Supply chains, in particular telecom supply chains, have undergone major changes during the past decade and are still in turmoil. The uncertainty on the telecom market, and short product life cycles, make it very difficult to produce reliable forecasts of the required supply chain capacity.

There are many causes of uncertainty in the demand and supply of telecom services: new operators emerging, and the introduction of new third-generation telecom systems that are subject to governmental regulations regarding timing and geographical coverage, are causing a very fast ramp-up in volume; large orders must be delivered simultaneously to remote areas in different countries; new consumers are continuously added, geographically (new countries) and in markets (e.g., transmission of data), in consumer segments (e.g., teenagers, children and senior citizens) and in technology (shift from second-generation to third-generation technology). On the whole, the telecom market is highly unpredictable and evolves very fast, making it extremely difficult to forecast demand accurately. Consequently, supply chain partners are constrained to undergo risks that grow quickly if not shared between actors and if the supply chain is not reactive. These risks include stock-outs, customer dissatisfaction, overstocks, expensive investments in technology that can become quickly obsolete, etc.

One of the possible solutions for better decision-making and the improvement of local and global performances is the establishment of cooperation in the supply chain. Our approach consists in proposing a system and methodology to evaluate the risk of the actor's behaviour (capacity-requirements-planning behaviour, supply behaviour) in relation to the performance of other actors and the supply chain.

In the remainder of this paper, we first review the previous work on cooperation in supply chains (Section 2). Then, we outline the context of the study (telecom supply chain) and the research approach (Section 3). Later on, we detail the potential of 
the system we are developing (Section 4) and the methodology (Section 5) we propose to help manage the risks undergone and to improve performance. Then, we present (Section 6) the setup of this methodology based on an example.

\section{Previous work}

Recently, many organisations have emerged to encourage trading partners to establish collaborative interactions (that rationalise or integrate their demand forecasting/ management, and reconcile the order-book processes) and to provide standards (that could support collaboration processes): RosettaNet (Rosetta, 2005), Voluntary Inter-industry Commerce Standards Association (Cpfr, 2005; Nix et al., 2004), Odette, etc. At the same time, scientific literature provides many interesting papers dedicated to cooperation study and analysis.

Moreover, many recent papers have been devoted to the study and analysis of cooperation in supply chains (Aviv, 2001; Agrawal and Seshadri, 2000; Cachon and Fisher, 2000; Cachon, 2001a; Dudek and Stadtler, 2004). Under the heading of cooperation, authors list several concepts, such as sales' forecasts sharing (Aviv, 2001; Dudek and Stadtler, 2004), the supply chain actor's agreement on inventory control, as in Axsäter (2001; 2003). In these papers, actors seek to improve the supply chain's global performance and not only the local performance. Some studies focus on the case of two sites (a factory and its supplier) (Dudek and Stadtler, 2004; Telle, 2003) while others focus on configurations including a factory and several retailers (Cachon and Fisher, 2000; Cachon, 2001a; Chen et al., 2001a; Chen et al., 2001b; Klastorin et al., 2002; Raghunathan, 2003; Dudeck and Stadtler, 2004).

Cooperation is thus carried out on several aspects of the relationship, such as orders which are traditionally oversized. For example, in Cachon and Lariviere (2001b), the customer does not have confidence in his supplier capacity and thus places orders higher than his real need to be sure of satisfaction. The supplier, aware of such practices, deliberately produces a quantity lower than the orders to avoid overstocks. Consequently, all the quantities are false. To avoid this situation, a framework for sharing information was proposed. Similarly, a retailer who wants to minimise the unsold goods' quantities orders lower quantities than what he thinks will be sold. Agrawal and Seshadri (2000) study a system for sharing risks in order to sell more goods and consequently increase the benefit. In the field of semiconductor manufacturing, Mallik and Harker (2004) study the problem of cooperation for capacity allocation using an intrafirm approach.

Nevertheless, less attention has been devoted to the risk evaluation of these new collaborative processes. Therefore, we propose a simulation system (LogiRisk) and a methodology that should help decision-makers of telecom supply chains to define cooperation models on capacity planning.

\section{Context of the study and research approach}

This paper focuses on supply chains of electronic products dedicated to telephone and telecommunications. In these supply chains, products share the same mode of networking. They also share the same types of actors and the same mode of circulation of 
physical and informational flows. This work is motivated by the collaboration with a SemiConductor Supplier's manager, who is concerned with setting up cooperation strategies in telecom supply chains.

In the following sections, we consider a generic chain based on maximum similarities between the telecom supply chains. Apart from the final users, the supply chain under study (see Figure 1) calls upon five types of actors (Agrell et al., 2004):

1 The Global Operators (GOs) (e.g., France Telecom, Vodafone, Telefonica) are responsible for the deployment of network coverage and associated services provided to the customers (Henten et al., 2003).

2 The Original Equipment Manufacturer (OEM) (e.g., Nokia, Ericsson, Lucent) manufactures the different equipment: drivers, printers, monitors, mobile phones, etc. (Berggren and Bengtsson, 2004).

3 The Electronics Manufacturing Services (EMS) provider (e.g., Solectron, Flextronics) resells assembled products to some partners who incorporate them into their own configurations and market them under their own trademark (Chen et al., 2004; Ren et al., 2003).

4 The Second-Tier Supplier or SemiConductor Supplier (SCS) (e.g., Freescale, Philips, Texas Instrument) manufactures the basic electronic components (chips) used by the EMS (Mallik and Harker, 2004).

5 The Third-Tier Suppliers are suppliers of raw materials needed in the fabrication of chips (e.g., silicon, chemical products).

Figure 1 Telecom supply chain structure

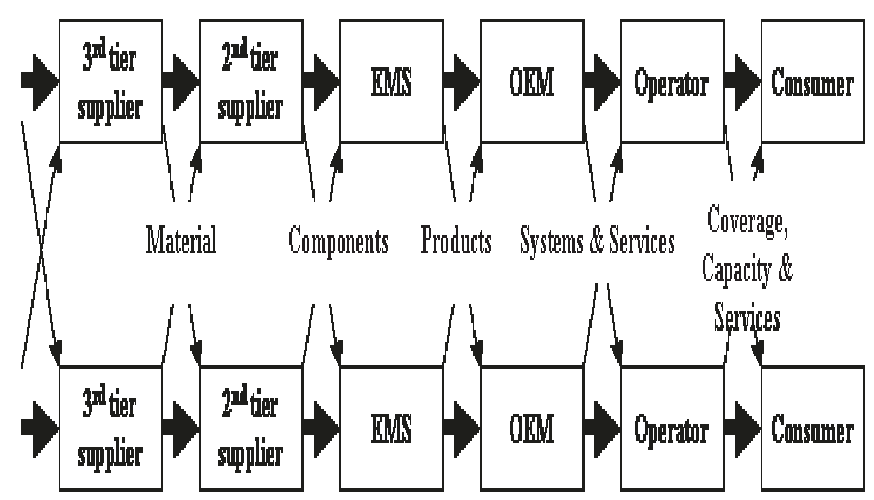

Source: Agrell et al. (2004)

The products involved in a telecom supply chain (telecommunication infrastructure products, mobile phone, etc.) have very short life cycles requiring a strong reactivity on the part of the various actors in order for them to deliver the right quantities in the right time 'window'. If the product is available only outside the right time 'window', several phenomena are observed: important price falls, sales volume falls, inventory obsolescence, etc. In short, one should note three main characteristics for the telecom supply chain (Insight Research Corporation, 2001; Lee, 2002; Agrell et al., 2004): 
1 Uncertainty of demand - the emergence of new actors in the supply chain (e.g., new global operators who enter the market and who consequently modify the distribution of the market shares), the uncontrolled exchange of information, the difficulties of the installation of reliable processes of coordination and collaboration in the chain and the absence of contractual structures binding the actors of the chain, which make the demand uncertain.

2 Instability - the demand fluctuates according to season, fashion phenomena and national and international events.

3 Short life cycle products - big technological shifts (shift from second-generation technology to third-generation technology) drastically reduce the product's life cycle.

All these factors generate a very big ramp-up of the demand, making it extremely difficult to develop accurate forecasts to anticipate market trends, and also making it difficult in general to develop efficient planning processes (demand planning, capacity planning, and so on). Added to that, we should notice that GO, OEM or EMS capacity can evolve rapidly. But SCS capacity changes are staggered, as they are dependent on heavy investments for the acquisition of wafer fabrication sites.

This telecom business operational environment underlines the need for a cooperation process in capacity negotiation between the SCS actor and the rest of the supply chain. In this context, the approach we adopt consists in initiating a discussion between the decision-makers of different supply chain entities (i.e., enterprises) in order to propose cooperation models for the Sales and Operations Planning (S\&OP) process elaboration. A simulation system is being developed to evaluate the impact of alternative cooperation models on supply chain performance in particular, according to different demand scenarios. These cooperation models are characterised by:

- on the one hand, the content of the exchange or the sharing between the actors (data such as forecasts, demand and inventory level, and/or treatment such as calculation procedure, constraints and criteria)

- on the other hand, by the way in which the decision-makers do the exchange or the sharing: occasional exchanges, permanent sharing, sequenced and formalised exchanges.

Moreover, the characteristics of the telecom supply chain led us to be interested in the evaluation of the risks associated with more or less cooperation. Our objective is to help decisions-makers define a cooperation approach by iteratively estimating each of the actors' risks: we mainly study the processes involved in setting up for capacity and the process of forecasts' communication (see Section 6 for an example). Our focus is primarily on a customer/supplier relationship involving a SemiConductor Supplier and an Original Equipment Manufacturer. 


\section{LogiRisk - a system for risk evaluation and collaboration enhancement}

In this section, we present the potential usefulness of LogiRisk and develop its methodology in setting up cooperation policies. Such policies result from the type and the quality of the information exchanged between the supply chain actors, and by the way the information is used by each actor for production and supply management.

\subsection{Relationship under study}

For simplicity, we focus on a customer/supplier relationship including:

- a SemiConductor Supplier

- an Original Equipment Manufacturer.

In order to make the system complete, all the other customers of the SCS are aggregated and presented by one unique actor: 'other OEMs' with perfect supply behaviour (i.e., the sent orders are always identical to the transmitted supply plan) (see Figure 2).

Figure 2 The customer/supplier relationship

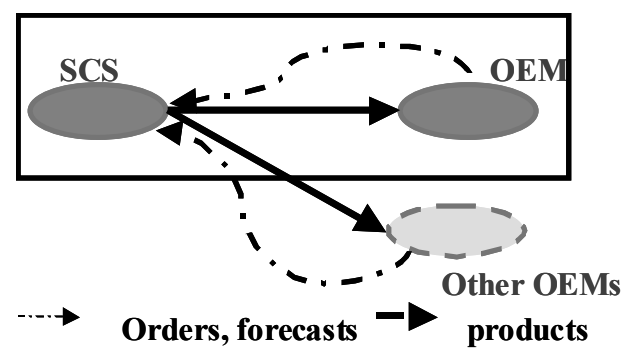

\subsection{Actors' behaviour models}

Capacity adjustment decisions are crucial for the SCS because of its long cycle times. Therefore, we are interested in capacity variation policies of the SCS (increasing or decreasing capacity). On the other hand, we suppose that the OEM is able to adapt its capacity whenever it is needed. So, the OEM focuses on its supply policies that are concerned with the forecasts it sends to the SCS compared to its original supply plan.

For each entity, the modelled processes are given in Figure 3 and detailed below. The notations and equations that formalise these processes are gathered in Section 4.2.6. For simplicity, we suppose that the S\&OP and the 'Production Planning and Launching' (PPL) processes are made at the same frequency (every $n$ time periods).

\subsubsection{SCS's sales and operation planning process and capacity policy}

During this process, the SCS makes its own interpretation of the supply plan and orders transmitted by the OEM to estimate its load for each planning period in the planning horizon. In the first step, the S\&OP process is made with infinite capacity: no load smoothing is considered. This results in a capacity proposal that must be validated or modified by top management throughout their capacity policy. 
Equations (1-4) define the S\&OP process made at time $\theta$.

Equation (1) defines the initial inventory of the S\&OP planning. Equation (2) defines the suggested minimal quantity of lots to be launched. Equation (3) defines the suggested production to be launched. Equation (4) expresses the inventory balance between two successive periods.

Figure 3 OEM and SCS processes models

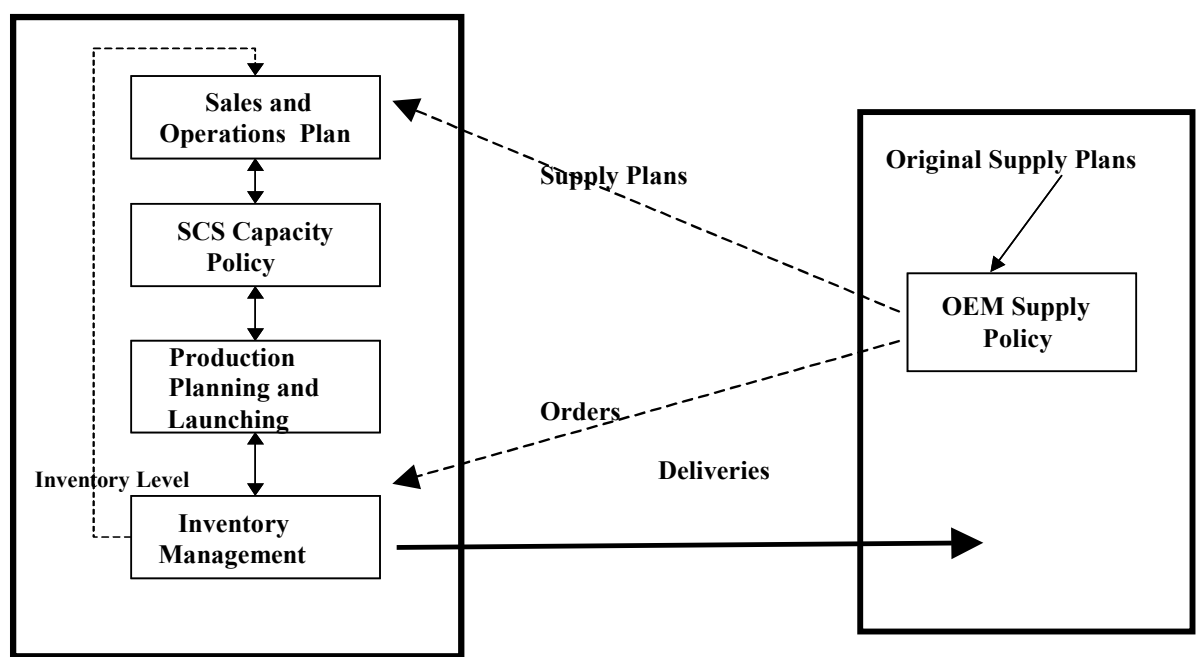

At this point, the SCS decides the necessary capacity, Capa $_{t}{ }_{t}$ in Equation (5), basing on its capacity variation policy (function $\mathrm{h}($.$) ) and the estimated loads. Various functions \mathrm{h}($. will be detailed when defining the SCS decision-maker's behaviour in the application.

\subsubsection{SCS's production planning and launching}

With respect to the determined capacity, the SCS schedules its production and launches the production orders. Because of long lead times, the SCS orders its production and therefore launches its production using forecasts arising from its customers.

Equations (6-9) define the Production Planning and Launching plans with respect to the determined capacity. They are an extension of the S\&OP equations.

\subsubsection{SCS's inventory management}

This process manages the real demand from the OEMs, the real inventory and the stock-outs between two planning processes (between time $\theta$ and time $\theta+\mathrm{n}$ ). It defines the initial data for the planning processes performed at time $\theta+\mathrm{n}$. Equations (10) and (11) express the real inventory and the stock-out from the inventory balance between two time periods.

The total quantity delivered is given by the demanded quantity and the stock-out variation, as shown in Equation (12). 
We suppose the SCS delivers to its different customers a quantity which is proportional to their respective demands (Equations (13) and (15)).

The stock-outs are the result of the difference of what was due and what has been delivered (Equations (14) and (16)).

Finally, some of the planned orders are opened and will be available as schedule receipts in the next plans (Equation (17)).

\subsubsection{OEM supply policy}

This process transforms one original supply plan elaborated by the OEM $O A v_{i, t}^{\theta}$, according to the OEM supply policy, to a new supply plan it transmits to the SCS $\left(A v_{i, t}^{\theta}\right)$. Added to this supply plan, the OEM transmits supply orders $\left(D_{i, \theta}\right)$ and receives in return the delivered quantities of products $\left(\operatorname{Del}_{i, \theta}\right)$.

We consider that the OEM may introduce an anticipation $(\delta)$ expressed in time periods between the original supply plan and the transmitted one, as shown in Equation (18).

\subsubsection{Supply chain uncertainties}

Handling the dynamic nature of the supply chain requires the development of a simulation model. In the simulation, as time passes, new information becomes available. This new information is taken into account by the actors in their behaviour and decision process.

Our simulation model, a Discrete-event Simulation model (Schriber and Brunner, 1997), takes into account two distinct sources of uncertainty: the OEM demand and the SCS process (see Figure 4).

Figure 4 A schematic view of the simulation model

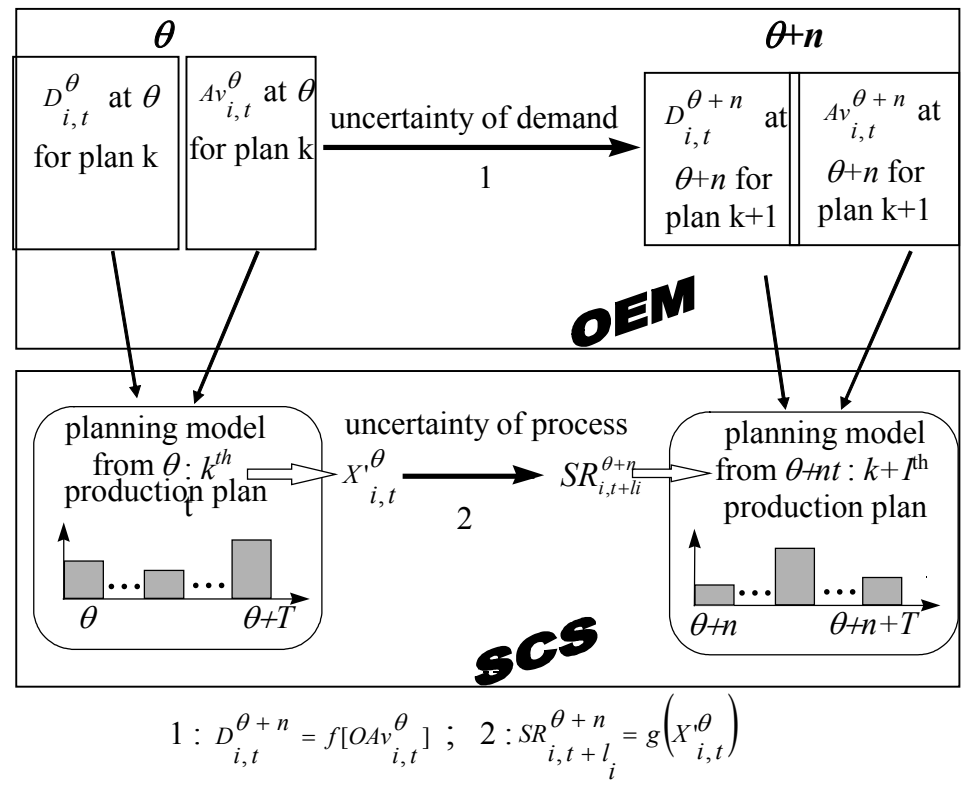


Between two successive production-planning processes of the SCS (done at time $\theta$ and $\theta+n$ ), new sets of firm orders and forecast orders will be received from the OEMs. The set of firm orders received between $\theta$ and $\theta+n$ will be added to the set of firm orders already planned at $\theta$. On the other hand, forecast orders received between $\theta$ and $\theta+n$ will replace the forecast orders available at $\theta$. Because the forecast orders known at $\theta+n$ will fit more or less with the set of firm orders known at $\theta$, the uncertainty of demand is introduced into the simulation model (Equation (19)).

In the same way, uncertainty of the SCS process means that open order $\left(\mathrm{X}^{\prime}\right)$ will not exactly result in Scheduled Receipt (SR) after a production lead time. This is translated in Equation (17.1), which replaces Equation (17).

Therefore, function $\mathrm{f}($.$) models the OEM uncertainty on demand, while function \mathrm{g}($. models the uncertainty in the SCS process. These might change depending on the type of scenario decision-makers want to simulate. Examples of functions $f($.$) and g($.$) are$ presented in the application.

\subsubsection{Actor's behaviour equations}

Let us consider the following notations:

$$
\begin{aligned}
& \theta=\text { date at which a planning process is realised } \\
& T=\text { horizon of the planning process } \\
& n=\text { number of time periods between two planning processes } \\
& N=\text { set of finished products sold by the SCS to the OEMs } \\
& D_{i, t}\left(\text { resp. } D o_{i, t}\right)=\text { firm orders of product } i \text { purchased by the OEM (resp; Other } \\
& \text { OEMs) at time } t \\
& O A v_{i, t}^{\theta}=\text { original supply plan that the OEM computes at time } \theta \text { before the } \\
& \text { application of its supply policy } \\
& A v_{i, t}^{\theta}=\left(\text { resp. } A v o_{i, t}^{\theta}\right) \text { forecast orders of product } i \text { for time } t \text { transmitted by } \\
& \text { the OEM (resp. 'other OEMs') } \\
& \delta=\text { OEMs' anticipation of its original supply plan to transmit it to } \\
& \text { the SCS } \\
& S R_{i, t}^{\theta}=\text { Schedule Receipt during period } t \text { of already open orders of item } i \\
& \text { at time } \theta \\
& \bar{I}_{i, \theta}=\text { real inventory of item } i \text { at the beginning of time } \theta \\
& I_{i, \theta}=\text { stock-out of item } i \text { at the beginning of time } \theta \\
& \operatorname{Lot}_{i}=\text { a produced quantity must be a multiple of this lot size } \\
& l_{i}=\text { minimum lead time of item } i \\
& r_{j}=\text { SCS Capacity ramp-up must be a multiple of this value } \\
& \mathrm{Capa}_{i, t}^{\theta}=\text { SCS Capacity during time period } t \text { computed at time } \theta \text { and } \\
& \text { allocated to product } i \text {. } \\
& \Delta=\text { anticipation of the capacity compared to the planned load } \\
& L_{j}=\text { minimal lead time between the decision to acquire resource } j \text {, and } \\
& \text { the availability of the new capacity } \\
& X_{i, t}^{\theta}\left(\text { resp. } X_{i, t}^{\prime \theta}\right)=\text { production quantity of item } i \text { to launch in production during time } \\
& \text { period } t \text { with infinite (resp. finite) capacity } \\
& I_{i, t}^{\theta}\left(\text { resp. } I_{i t}^{\prime \theta}\right)=\text { estimated inventory of item } i \text { at the beginning of time } t \text { with } \\
& \text { infinite (resp. finite) capacity }
\end{aligned}
$$


$k_{i, t}^{\theta}\left(\right.$ resp. $\left.k_{i, t}^{\prime \theta}\right)=$ minimal number of lots of item $i$ to be produced during time $t$ with infinite (resp. finite) capacity

$D l_{i, t}=$ total quantity of item $i$ delivered to the SCS customers

$I_{1_{i, \theta}}^{-}\left(\right.$resp. $\left.I_{2_{i, \theta}}^{-}\right)=$shortage of item $i$ for the OEM (resp. for the 'other OEMs') at time $\theta$

$D l 1_{i, \theta}\left(\right.$ resp. $\left.D l 2_{i, \theta}\right)=$ Quantities of item $i$ delivered to the OEM (resp. 'Other OEMs') at time $\theta$

[]$^{+}=$the upper integer positive value operator

$$
\begin{aligned}
& I_{i, \theta}^{\theta}=\bar{I}_{i, \theta}-I_{i, \theta}^{-} \\
& \text {for } t \in[\theta, \theta+T] \\
& k_{i, t}^{\theta}=\left[\left(A v_{i, t}^{\theta}+A v o_{i, t}^{\theta}-S R_{i, t}^{\theta}-I_{i, t}^{\theta}\right) / \operatorname{lot}_{i}\right]^{+} \\
& \text {for } t \in[\theta, \theta+T] \\
& X_{i, t}^{\theta}=k_{i, t+l_{i}}^{\theta} \times \operatorname{lot}_{i} \\
& \text { for } t \in[\theta, \theta+T] \\
& I_{i, t+1}^{\theta}=I_{i, t}^{\theta}+X_{i, t-l_{i}}^{\theta}-A v_{i, t}^{\theta}-A v o_{i, t}^{\theta}+S R_{i, t}^{\theta} \\
& \text { for } t \in[\theta, \theta+T] \\
& \operatorname{Capa}_{i, t}^{\theta}=h\left(X_{i, t}^{\theta}, \sum_{i} X_{i, t}^{\theta}, \sum_{i} \operatorname{Capa}_{i, t}^{\theta-n}\right) \\
& \text { for } t \in[\theta, \theta+T] \\
& I_{i, \theta}^{\prime \theta}=\bar{I}_{i, \theta}-I_{i, \theta}^{-} \\
& k_{i, t}^{\prime \theta}=\left[\left(I_{i, t}^{\prime \theta}-A v_{i, t}^{\theta}-A v o_{i, t}^{\theta}+S R_{i, t}^{\theta}\right) / \text { lot }_{i}\right]^{+} \quad \text { for all } t \in[\theta, \theta+T] \\
& X_{i, t}^{\prime \theta}=\min \left(k_{i, t+l_{i}}^{\prime \theta} \times \operatorname{lot}_{i} ; \operatorname{Capa}_{i, t}^{\theta}\right) \quad \text { for all } t \in[\theta, \theta+T] \\
& I_{i, t+1}^{\prime \theta}=I_{i, t}^{\prime \theta}+X_{i, t-1_{i}}^{\prime \theta}-A v_{i, t}^{\theta}-A v o_{i, t}^{\theta}+S R_{i, t}^{\theta} \quad \text { for all } t \in[\theta, \theta+T] \\
& \bar{I}_{i, t+1}=\operatorname{MAX}\left(0 ; \bar{I}_{i, t}+X_{i, t-l_{1}}^{\prime \theta}+S R_{i, t}^{\theta}-D_{i, t}-D o_{i, t}-I_{i, t}^{-}\right) \quad \text { for } t \in[\theta, \theta+n-1] \\
& I_{i, t+1}^{-}=\bar{I}_{i, t+1}-\left(\bar{I}_{i, t}+X_{i, t-l_{i}}^{\prime \theta}+S R_{i, t}^{\theta}-D_{i, t}-D o_{i, t}-I_{i, t}^{-}\right) \quad \text { for } t \in[\theta, \theta+n-1] \\
& D l_{i, t}=D_{i, t}+D o_{i, t}+I_{i, t}^{-}-I_{i, t+1}^{-} \quad \text { for } t \in[\theta, \theta+n-l] \\
& D l_{1_{i, t}}=D l_{i, t}\left(\left(D_{i, t}+I_{1_{i, t}^{-}}^{-}\right) /\left(D_{i, t}+D o_{i, t}+I_{i, t}^{-}\right)\right) \quad \text { for } t \in[\theta, \theta+n-l] \\
& I_{1_{i, t+1}}^{-}=D_{i, t}+I_{1_{i, t}}^{-}-D l_{1_{i, t}} \\
& \text { for } t \in[\theta, \theta+n-1] \\
& D l_{2_{i, t}}=D l_{i, t}\left(\left(D_{i, t}+I_{2_{i, t}^{-}}^{-}\right) /\left(D_{i, t}+D o_{i, t}+I_{i, t}^{-}\right)\right) \quad \text { for } t \in[\theta, \theta+n-1] \\
& I_{2_{i, t+1}}^{-}=D o_{i, t}+I_{2_{i, t}^{-}}^{-}-D l_{2_{i, t}} \\
& \text { for } t \in[\theta, \theta+n-1] \\
& S R_{i, t+l_{i}}^{\theta+n}=S R_{i, t+l_{i}}^{\theta}+X_{i, t}^{\prime \theta} \\
& \text { for } t \in\left[\max \left(\theta, \theta+n-l_{i}\right), \theta+n\right] \\
& S R_{i, t+l_{i}}^{\theta+n}=S R_{i, t+l_{i}}^{\theta}+g\left(X_{i, t}^{\prime \theta}\right) \\
& \text { for } t \in\left[\max \left(\theta, \theta+n-l_{i}\right), \theta+n\right]
\end{aligned}
$$




$$
\begin{array}{lr}
A v_{i, t}^{\theta}=O A v_{i, t+\delta}^{\theta} & \text { for all } i, \theta \text { and } t>\theta \\
D_{i, t}=f\left(O A v_{i, t}^{\theta}\right) & \text { for all } i, \theta \text { and } \theta \leq t<\theta+n
\end{array}
$$

\subsection{Performance indicators of the simulation}

Simulations' performance indicators aim at tracing the various types of cost incurred by the SCS and the OEM. They are synthesised in Table 1:

Table 1 Performance indicators of the simulation

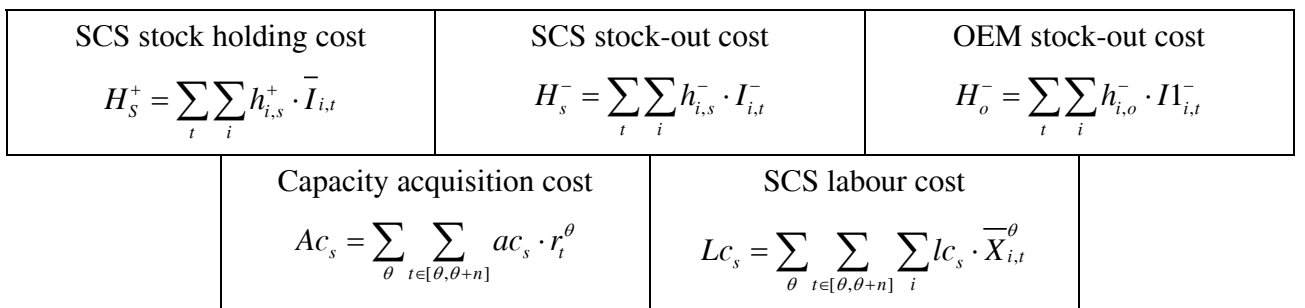

where:

$h_{i, s}^{+}=$unitary SCS holding cost of product $i$

$h_{i, s}^{-}=$unitary SCS stock-out cost of product $i$

$h_{i, o}^{-}=$unitary OEM stock-out cost of product $i$

$a c_{s}=$ SCS capacity acquisition cost corresponding to one ramp-up $\left(r_{j}\right)$

$l c_{s}=$ SCS unitary labour cost

$r_{t}^{\theta}=$ capacity ramp-up number at period $t$ determined by the plan processed at $\theta$.

\section{LogiRisk and its associated methodology}

The cooperation process using LogiRisk can be described (Figure 5) in a five-step methodology (Telle et al., 2003):

1 In Step 1, the concerned decision-makers together select the problem to be considered, and the model of the customer/supplier relationship(s) under study is built. For example, the problem under study could be the evaluation of the risks related to the transmission of optimistic or pessimistic supply plans.

2 In Step 2, the simulation experimental process is defined simultaneously by the two actors, depending on the problem to be studied. The cooperation policies to be considered are defined. A set of simulations is planned.

3 Step 3 consists in running a series of simulations.

- For each policy, each actor defines the values of the parameters associated with the policy.

- The system performs simulations and computes the global and individual risks of the policy. 
4 In Step 4 each actor will individually be able to analyse the risks of the policies.

5 On the other hand, in Step 5 a common analysis on the basis of global indicators will allow the validation of the chosen cooperation process.

Figure 5 Implementation methodology

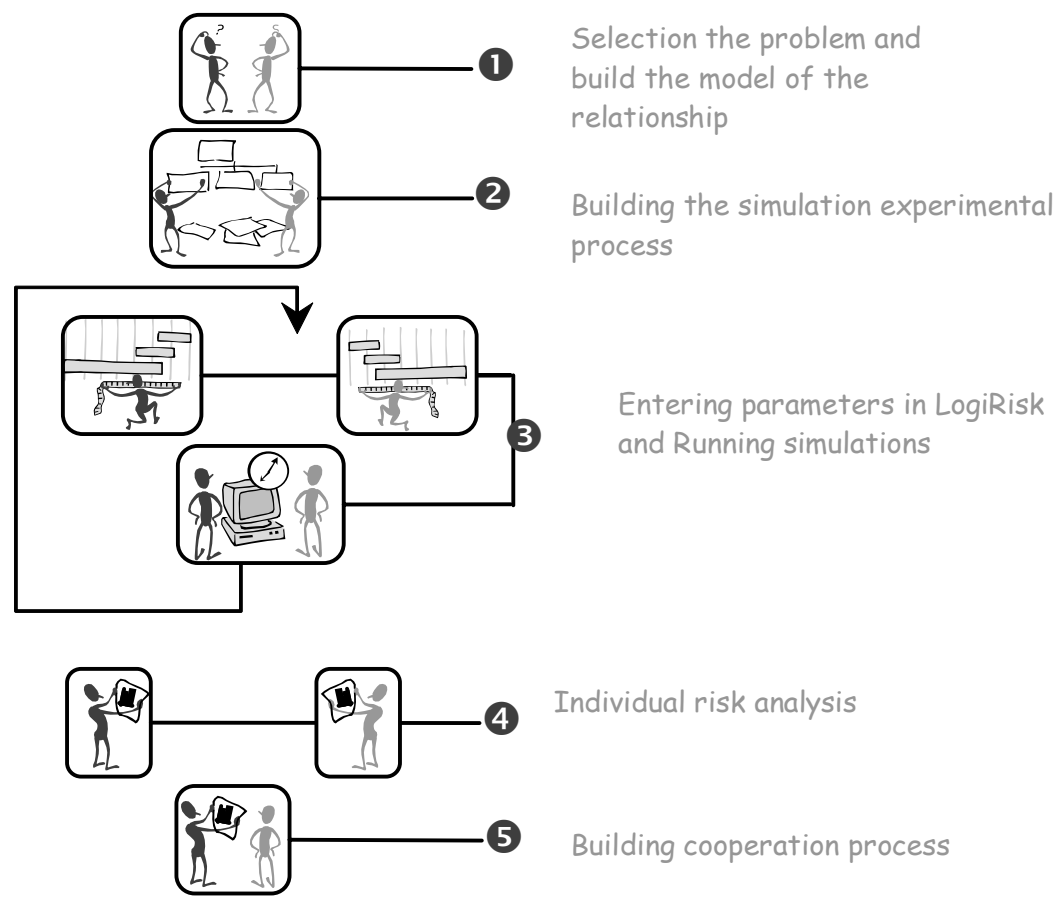

\section{Implementation of the methodology based on an example}

\subsection{Selection of the problem}

The problem under study is the setting up of the capacity for the SemiConductor Supplier and the forecasts' communication process for the Original Equipment Manufacturer. Each product has its own dedicated manufacturing process.

\subsection{Building the simulation experimental process}

In this implementation, the SCS either aligns the capacity with the planned load (Equation (20a)) or maintains the capacity previously defined (Equation (20b)). It can also anticipate the capacity of a $\Delta$. Finally, when the available capacity is not sufficient, the capacity is allocated to each product according to its proportion of the planned load.

$$
\operatorname{Capa}_{i, t-\Delta}^{\theta}=\frac{X_{i, t}}{\sum_{i} X_{i, t}}\left[\frac{\sum_{i} X_{i, t}}{r_{j}}\right]^{+} \cdot r_{j} . \quad \text { if } t \geq \theta+\Delta+L_{j} .
$$




$$
\operatorname{Capa}_{i, t-\Delta}^{\theta}=\frac{X_{i, t}}{\sum_{i} X_{i, t}} \sum_{i} \operatorname{Capa}_{i, t}^{\theta-n} \quad \text { if } t<\theta+\Delta+L_{j}
$$

Different policies for changing the capacity will be considered for the SCS.

1 The capacity is aligned at time $t$ with the planned load. The acquired extra capacity is equal to the minimum number of 'capacity ramp-up' increments that enable the planned production: $\Delta=0, L_{j} \neq 0$.

2 A fixed capacity is maintained throughout the planning process: $\Delta=0, L_{j} \neq \infty$.

3 The capacity is increased $\Delta$ periods before the planned load needs it. The amount of extra capacity acquisition corresponds to a minimum number of 'capacity ramp-up' enabling the required production: $\Delta>0, L_{j} \neq 0$.

For the OEM, two main policies are considered:

1 The OEM supply plan is reliable (the orders and the OEM original supply plan are similar), and the following communication policies are considered in Equation (18):

- The supply plan transmitted to the SCS is identical to the original OEM supply plan: $\delta=0$.

- The supply plan transmitted to the SCS is late compared to the original OEM supply plan: $\delta>0$.

- $\quad$ The supply plan transmitted to the SCS is advanced compared to the original OEM supply plan: $\delta<0$.

2 The original OEM supply plan is communicated to the SCS as it is ( $\delta=0$ in Equation (18)), but it is not reliable (Equation 19). Two cases are considered:

- The OEM supply plans a supply rise whereas the transmitted orders remain stable: $\mathrm{f}(\mathrm{x})=$ constant.

- $\quad$ The OEM supply plan envisages a rise whereas the transmitted orders fall: $\mathrm{f}(\mathrm{x})=$ constant $-\mathrm{x}$.

\subsection{Entering parameters and running the simulation}

At this step, decision-makers feed LogiRisk with the parameters associated with the policies and data and each runs its simulation.

In our example, the planning parameters are set out in Table 2. Table 3 gives the respective unitary costs for the SCS and the OEM.

Table 2 Planning parameters

\begin{tabular}{cccccc}
\hline $\bar{I}_{i, 1}$ & $S R_{i, 1}^{1}, S R_{i, 2}^{1}, S R_{i, 3}^{1}$ & $\operatorname{Lot}_{i}$ & $l_{i}$ & $L_{j}$ & $r_{j}$ \\
\hline 0 & 700 & 10 & 3 & 5 & 100 \\
\hline
\end{tabular}


Table 3 Unitary costs

\begin{tabular}{lccccc}
\hline & $h_{i, s}^{+}$ & $h_{i, s}^{-}$ & $a c_{s}$ & $l c_{s}$ & $h_{i, o}^{-}$ \\
\hline SCS & 3 & 10 & 2000 & 7 & \\
OEM & & & & & 20 \\
\hline
\end{tabular}

\subsection{SCS risk analysis}

For each of its policies, the SCS defines a number of possible scenarios of the OEM behaviour.

The probability of occurrence of these scenarios is evaluated according to the SCS expertise on the five-rank scale given by Table 4 .

Table 4 Probability assessment scale

\begin{tabular}{lll}
\hline Rank & Subjective estimate & Description \\
\hline 1 & Very unlikely & Very rare event \\
2 & Improbable & There is indirect evidence of event \\
3 & Moderate & There is direct evidence of event \\
4 & Probable & There is strong direct evidence of event \\
5 & Very probable & Event recurs frequently \\
\hline
\end{tabular}

The performance corresponding to each scenario can be evaluated thanks to the LogiRisk simulations. Thereafter, the risks related to the choice of such a policy can be computed.

The SCS evaluates the risks of the following policies:

1 SCS Policy 1 - consisting in increasing the capacity as soon as the planned load exceeds the capacity.

2 SCS Policy 2 - maintaining a fixed capacity.

3 SCS Policy 3 - the capacity is increased $\Delta=1$ periods before the planned load exceeds the capacity, depending on different scenarios:

- Scenario 1 - the OEM supply order trends are identical $(\delta=0$ and $f(x)=x)$ to that indicated by the transmitted supply plan (the original supply plan, which is reliable, is transmitted).

- Scenario 2 - the OEM supply plan transmitted to the SCS is late compared to the real supply plan of the OEM $(\delta=-1$ and $\mathrm{f}(\mathrm{x})=\mathrm{x})$ and the supply orders follow the original supply plan.

- Scenario 3 - the OEM supply plan transmitted to the SCS is advanced compared to the real supply plan of the OEM $(\delta=1$ and $\mathrm{f}(\mathrm{x})=\mathrm{x})$ and the supply orders follow the original supply plan.

- Scenario 4 - the OEM supply orders remain stable, whereas the transmitted supply plan (the original supply plan, which is poor, is transmitted) envisages a rise $(\delta=0$ and $\mathrm{f}(\mathrm{x})=$ constant $)$. 
- Scenario 5 - the OEM supply orders fall, whereas the supply plan the OEM transmitted (he transmits the original supply plan, which is poor) envisages a rise $(\delta=0$ and $f(x)=$ constant $-x)$.

Table 5 gives the corresponding risk evaluation for each of the SCS policies mentioned above. This risk evaluation is associated with the probability indexes defined below.

Table 5 SCS policies evaluation

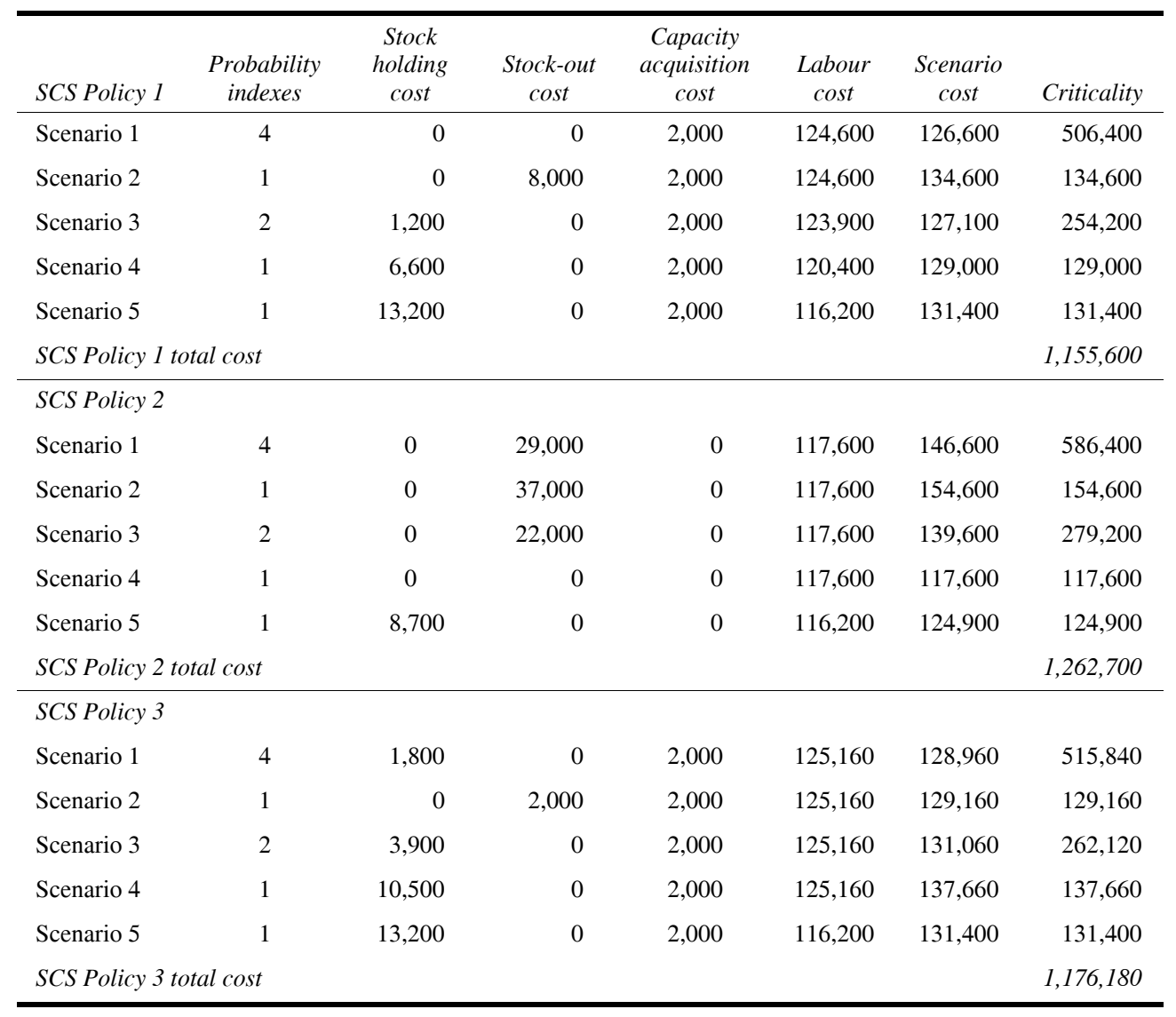

The results above show that the SCS minimises his risks if he increases his capacity as soon as the planned load exceeds capacity (Policy 1). This is logical, since this policy insures cost savings at inventory and capacity levels. The risk in choosing Policy 3 is greater because it generates greater holding costs. Finally, the risk related to the choice of Policy 2 seems the greatest because the fixed capacity is so low that it could not cover the orders. This would not be true if Scenario 1 was not really the most probable. In short, the occurrence probabilities that the decision-maker defines, depending on his expertise, very much influence the conclusions he can gather. So this evaluation has to be done a priori. 


\subsection{The OEM risk analysis}

In the same way as in Section 6.4, for each of his policies, the OEM defines a number of possible scenarios of the SCS policies. The probability of occurrence of these scenarios is evaluated using his expertise. The performance corresponding to each scenario can be evaluated thanks to the LogiRisk simulations. Thereafter, the risks related to the choice of each OEM policy can be computed.

The OEM evaluates the risks of the following policies:

1 OEM Policy 1 - the supply plan transmitted to the SCS is identical to the orders $(\delta=0)$.

2 OEM Policy 2 - the supply plan transmitted to the SCS is identical to the orders but late $(\delta=-1)$.

3 OEM Policy 3 - the supply plan transmitted to the SCS is equal to the orders but advanced $(\delta=1)$ depending on different scenarios:

- Scenario 1 - the SCS makes the choice of a policy consisting in increasing the capacity as soon as the planned load exceeds the capacity.

- Scenario 2 - the SCS makes the choice of fixing its capacity.

- Scenario 3 - the SCS makes the choice of anticipating the needed quantities.

Table 6 gives the corresponding risk evaluation for each of the SCS policies mentioned above. This risk evaluation is associated to the probability vector defined below.

Table 6 OEM policies evaluation

\begin{tabular}{lrrrr}
\hline OEM Policy 1 & Probability indexes & Stock-out cost & Scenario cost & Criticality \\
\hline Scenario 1 & 5 & 0 & 0 & 0 \\
Scenario 2 & 1 & 28,815 & 28,815 & 28,815 \\
Scenario 3 & 3 & 0 & 0 & 0 \\
OEM Policy 1 total cost & & & & 28,815 \\
\hline OEM Policy 2 & 5 & 0 & 0 & 0 \\
Scenario 1 & 1 & 244,893 & 244,893 & 244,893 \\
Scenario 2 & 3 & 0 & 0 & 0 \\
Scenario 3 & & & & 244,893 \\
OEM Policy 2 total cost & & 12,841 & 12,841 & 64,205 \\
\hline OEM Policy 3 & 5 & 28,815 & 28,815 & 28,815 \\
Scenario 1 & 1 & 8,461 & 8,461 & 25,383 \\
Scenario 2 & 3 & & & 118,403 \\
Scenario 3 & & & & \\
OEM Policy 3 total cost & & & & \\
\hline
\end{tabular}


The results above show that the OEM may perhaps find it beneficial to choose Policy 1 . Policy 2, which consists in sending a procurement plan which is late compared to the orders, does not allow the SCS to see the rise of the market and then to make the deliveries at the good times. Consequently, important stock-outs occur on the OEM side. This happens if one decides to choose a policy minimising the risk. If one decides to choose a policy minimising the maximum risk, then Policy 1 and Policy 3 are the ones to choose.

\subsection{Build cooperation process}

When commenting on the results of the simulation, both the SCS and the OEM actors can discuss their policies. What can be seen in our very simple example is that confidence leads to better results for both actors. Moreover, when an actor chooses a policy, simulations show the choices that his partner is induced to make: a biased policy induces another biased policy at the partner level.

Usually, actors justify their policies because of market uncertainty and unpredictability. LogiRisk enables us to show that even in an unstable environment, it is more reliable to offer clarity and transparency to the partners of the supply chain.

\section{Conclusion}

In this paper we have presented a system and set up a methodology to help and improve on the local and global performances in a two-stage telecom supply chain by convincing the different supply chain actors to set up cooperation policies. Future work should be devoted to more development of the actors' models and behaviour. Similarly, the approach can be consolidated by some pilot projects involving two decision-makers belonging to an OEM and a SCS company.

\section{References}

Agrawal, V. and Seshadri, S. (2000) 'Risk intermediation in supply chains', IIE Transaction, No. 32, pp.819-831.

Agrell, P.J., Lindorth, R. and Norman, A. (2004) 'Risk, information and incentives in telecom supply chains', Int. J. of Production Economics, Vol. 90, No. 1, pp.1-16.

Aviv, Y. (2001) 'The effect of collaborative forecasting on supply chain performance', Management Science, Vol. 47, No. 10, pp.1326-1343.

Axsäter, S. (2001) 'A framework for decentralized multi-echelon inventory control', IIE Transactions, No. 33, pp.91-97.

Axsäter, S. (2003) 'Optimal policies for serial inventory systems under fill rate constraints', Management Science, Vol. 49, No. 2, pp.247-253.

Berggren, C. and Bengtsson, L. (2004) 'Rethinking outsourcing in manufacturing: a tale of two telecom firms', European Management Journal, Vol. 22, No. 2, pp.211-223.

Cachon, G.P. (2001a) 'Stock wars: Inventory competition in a two echelon supply chain with multiple retailers', Operations Research, Vol. 49, No. 5, pp.658-674.

Cachon, G.P. and Fisher, M. (2000) 'Supply chain inventory management and the value of shared information', Management Science, Vol. 46, No. 8, pp.1032-1048. 
Cachon, G.P. and Lariviere, M.A. (2001b) 'Contracting to assure supply: how to share demand forecasts in a supply chain', Management Science, Vol. 47, No. 5, pp.629-646.

Chen, F., Federgruen, A. and Zheng, Y.S. (2001a) 'Coordination mechanisms for a distribution system with one supplier and multiple retailers', Management Science, Vol. 47, No. 5, pp.693-708.

Chen, F., Federgruen, A. and Zheng, Y.S. (2001b) 'Near optimal pricing and replenishment strategies for a retail/distribution system', Operations Research, Vol. 49, No. 6, pp.839-853.

Chen, R.R., Roundy, R.O., Zhang, R.Q. and Janakiraman, G. (2004) 'Efficient auction mechanisms for supply chain procurement', Management Science, Vol. 51, No. 2005, pp.467-482.

Cpfr (2005) http://www.cpfr.org, visited 26 October.

Dudek, G. and Stadtler, H. (2004) 'Negotiation-based collaborative planning between supply chains partners', European Journal of Operational Research, in Press.

Henten, A., Olesen, H., Saugstrup, D. and Tan, S.E. (2003) 'New mobile systems and services in Europe, Japan and South-Korea', The Stockholm Mobility Roundtable, Stockholm (Sweden), http://www.cti.dtu.dk/publications/workingpapers/ctiwp75.pdf, visited 26 October 2005.

Insight Research Corporation (2001) Supply Chain Management and Telecom Components: Construction, Electronic Equipment Packaging, Power Systems, and Wire \& Cable 2001-2006, Pub ID: IR1164630, p.152.

Klastorin, T.D., Moinzadeh, K. and Son, J. (2002) 'Coordinating orders in supply chains through price discounts', IIE Transactions, No. 34, pp.679-689.

Lee, H. (2002) 'Aligning supply chain strategies with product uncertainties', California Management Review, Vol. 44, No. 2, pp.105-119.

Mallik, S. and Harker, P.T. (2004) 'Coordinating supply chains with competition: capacity allocation in semiconductor manufacturing', European Journal of Operational Research, Vol. 159, No. 2, pp.330-347.

Nix, N.M., Zacharia, Z.G., Lusch, R.F., Bridges, W.R. and Thomas, A. (2004) Keys to Effective Supply Chain Collaboration: A Special Report from the Collaborative Practices Research Program, http://www.vics.org/committees/cpfr/white_papers, visited 26 October 2005.

Odette (2005) http://www.odette.org, visited 26 October 2005.

Raghunathan, S. (2003) 'Impact of demand correlation on the value of and incentives for information sharing in a supply chain', European Journal of Operational Research, No. 146, pp.634-649.

Ren, J.Z., Cohen, M.A., Terwiesch, C. and Ho, T. (2003) 'An empirical analysis of forecast sharing in the semiconductor equipment supply chain', Manufacturing and Service Operations Management, Vol. 5, No. 1, pp.70-73.

Rosetta (2005) http://www.rosettanet.org, visited 26 October 2005.

Schriber, T.J. and Brunner, D.T. (1997) 'Inside discrete-event simulation software: how it works and why matters', in S. Andradóttir, K.J. Healy, D.H. Withers and B.L. Nelson (Eds.) Proceedings of the 1997 Winter Simulation Conference.

Telle, O. (2003) 'Gestion de chaînes logistiques dans le domaine aéronautique: Aide à la coopération au sein d'une relation donneurs d'ordres/fournisseurs', PhD Thesis, Ecole Nationale Supérieure de l'Aéronautique et de l'Espace, Toulouse.

Telle, O., Thierry, C. and Bel, G. (2003) 'Modélisation macroscopique des systèmes de production pour la simulation de la relation donneurs d'ordres/fournisseurs dans les chaînes logistiques', 5th Industrial Engineering International Congress, Quebec. 